\title{
Fatigue life improvement of cast ZK60 Mg alloy through low temperature closed-die forging for automotive applications
}

\author{
SMH. Karparvarfard ${ }^{1, *}$, S.K. Shaha ${ }^{1}$, S.B. Behravesh ${ }^{1}$, H. Jahed ${ }^{1}$, and B. Williams ${ }^{2}$ \\ ${ }^{1}$ Deparment of Mechanical \& Mechatronics Engineering, University of Waterloo, 200 University Ave W, Waterloo, ON N2L 3G1, \\ Canada \\ ${ }^{2}$ CanmetMATERIALS, Natural Resources Canada, 183 Longwood Road South, Hamilton, ON L8P 0A1, Canada
}

\begin{abstract}
The influence of low-temperature closed-die forging on the quasi-static and cyclic behaviour of as-cast ZK60 magnesium alloy was investigated. As-cast ZK60 billets were forged at a ram speed of 20 $\mathrm{mm} / \mathrm{sec}$ and a temperature of $250{ }^{\circ} \mathrm{C}$. While the yield strength of the starting alloy was $139 \mathrm{MPa}$, the forging process improved the yield strength significantly by $\sim 68 \%$ to $234 \mathrm{MPa}$. Moreover, the stresscontrolled push-pull fatigue tests at the stress amplitudes of $140 \mathrm{MPa}$ to $180 \mathrm{MPa}$ revealed that the fatigue life was enhanced by an order of magnitude. Microstructural analyses besides the texture measurements at different locations of the forged part manifested partial grain refinement and texture modification strengthening mechanisms. It is believed that the fatigue life improvement is achieved in the wake of the grain refinement and the subsequent material strengthening.
\end{abstract}

\section{Introduction}

Concerns over the adverse impact of fossil fuels have driven the global transportation sector to change their products' structure through the widespread adoption of lightweight materials. Magnesium (Mg), as the lightest commercial metal available in the industry, can play an integral role in the lightweighting of multi-material vehicle architecture [1]. However, to date, the usage of this metal has been restricted to the non-load bearing components such as seat frames and housing parts [2]. Moreover, the dominant manufacturing process is diecasting for its economic benefits [3], whilst casting brings about abundant of defects in the microstructure of alloys like porosities and inclusions, deteriorating its mechanical properties. As a result, wrought $\mathrm{Mg}$ alloys are gaining interests to be utilized in vehicles in loadbearing components [4]-[8].

Among different manufacturing techniques, forging is of particular interest not only because it can lead to enhanced mechanical properties, but also it can form components with complicated geometries [9][10]. The monotonic and cyclic behaviour of different open dieand semi-closed die forged $\mathrm{Mg}$ alloys have been investigated so far [11]-[19]. The forging temperature at these studies were quite high, i.e., $\sim 450{ }^{\circ} \mathrm{C}$. However, to expand the applications of forged $\mathrm{Mg}$ alloys in high volume production passenger cars, it is crucial to carry out the manufacturing process at a lower temperature, for it be cost-effective. In this study, we investigated the influence of low-temperature closed-die forging on the quasi-static and fatigue response of as-cast ZK60. The forging temperature in this study was $250{ }^{\circ} \mathrm{C}$, which is less than that in previous studies, but also is high enough to achieve a crack-free material after the forging. Consequently, there is the need to better understand how the microstructure relates to the final mechanical properties, particularly the fatigue response, after low temperature forging.

\section{Material and Experiments}

Cylindrical billets of $63.5 \mathrm{~mm}$ diameter and $65 \mathrm{~mm}$ length were machined from a commercial as-cast ZK60 $\mathrm{Mg}$ alloy ingot $(5.8 \% \mathrm{Zn}, 0.61 \% \mathrm{Zr},<0.3 \%$ total others, and $\mathrm{Mg}$ as balance- analytical weight percent). The billets were gradually heated to the temperature of 250 ${ }^{\circ} \mathrm{C}$, and then transferred to a hydraulic press whose dies were also pre-heated to the same temperature. This was the lowest forging temperature for a crack-free sample [20]. The billet was forged into an I-beam shape [10] which allowed material flow in different directions at varying strain-rates. The forging was conducted at an initial ram speed of $20 \mathrm{~mm} / \mathrm{sec}$. To reduce friction between the billet and the die, a graphite lubricant was utilized. After forging, no heat treatment was employed, and the forged part was air- cooled to the room temperature. Figure 1 represents the forged part and the schematic locations of the dog-bone samples extracted from it. TD, LD, and FD (as shown in Figure 1) denote the radial, longitudinal, and forging directions, respectively. 
(a)

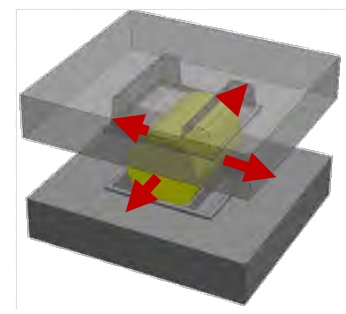

(b)

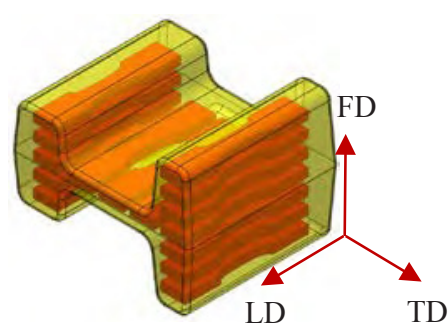

(c)

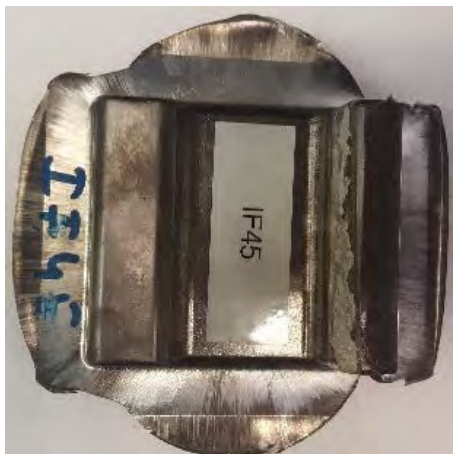

Fig. 1. (a) The schematic demonstration of the forging process of the as-cast billet; (b) the schematic representation of the final forged part and the location of dog-bone samples; (c) the photograph of the final closed-die forged part from the top view

Dog-bone samples were machined from different parts of the forged beam as shown schematically in Figure 1(b). Details about the geometry of the samples and the location of samples in the cast billet could be found in [11]. Quasi-static tests were carried out at the displacement rate of $1 \mathrm{~mm} / \mathrm{min}$. Strain was captured during these tests using ARAMIS 3D Digital Image Correlation (DIC) system with 5-megapixel resolution and the frame rate of $15 \mathrm{fps}$. Stress-controlled fully reversed $(R=-1)$ push-pull fatigue tests were performed under standard laboratory conditions, using an Instron 8874 servo-hydraulic frame with a load capacity of $\pm 25 \mathrm{KN}$ at three different stress amplitudes, $140 \mathrm{MPa}, 160 \mathrm{MPa}$, and $180 \mathrm{MPa}$. These stress amplitudes were chosen such that fatigue lives within the range of $10^{3}$ to $10^{5}$ cycles could be obtained. The test frequencies were $5 \mathrm{~Hz}, 10 \mathrm{~Hz}$, and $15 \mathrm{~Hz}$ for the tests at $180 \mathrm{MPa}, 160 \mathrm{MPa}$, and $140 \mathrm{MPa}$, respectively.

A Bruker D8 Discover X-ray diffractometer equipped with a $2 \mathrm{D}$-detector using $\mathrm{CuK} \alpha$ beam and a current of $40 \mathrm{~mA}$ was utilized to measure texture. The procedure for the microstructure analysis and texture measurement was the same as the one presented in [11]. Hardness testing was performed using a United TrueBlue Rockwell tester.

\section{Results and Discussion}

\subsection{Microstructure, texture, and hardness}

The microstructure and texture of the as-cast ZK60 have already been detailed in [11]. The cast alloy exhibited an average grain size of $131 \pm 26 \mu \mathrm{m}$. Moreover, the texture measurements indicated that the c-axis of the hexagonal close-packed (HCP) crystal structure of the grains are randomly oriented. Figure 2 displays the typical optical microscope (OM) microstructure and the collected (0002) and (1010) pole figures of the as-cast alloy.

For the microstructure and texture analyses of the forged part, samples were extracted from different locations on the mid-cross section of the I-beam. Figure 2 shows the microstructure of the forged material in the two flanges, and the web of the beam.
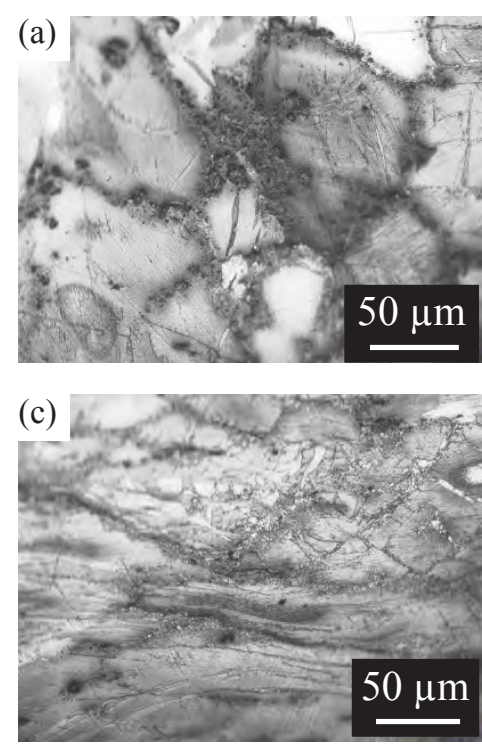

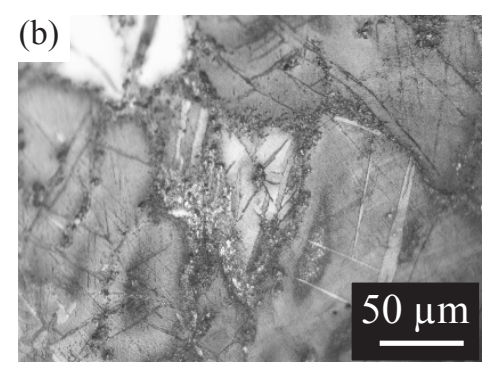

FD

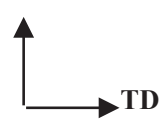

Fig. 2. The optical micrograph of forged ZK60 at (a) tall flange, (b) short flange, (c) and the web of the beam. The indicated directions apply to all figures.

According to Figure 2, the close-die forging brings about a bimodal grain structure in the forged alloy; i.e., elongated grains are surrounded by fine grains $(2-5 \mu \mathrm{m})$. This indicates that partial dynamic recrystallization (DRX) is happening [21]. The incomplete DRX can stem from that the low processing temperature and high deformation rate inhibit a complete recrystallization happening [21]. Moreover, it is reported that rare-earth materials in ZK60 can impede dislocation movement by their pinning effect leading to a partial DRX [22]. Another significant aspect of microstructure is that qualitatively the volume fraction of fine recrystallized grains is higher in the web of the I-beam forged alloy (Figure 2.c). This affects the mechanical behavior of the forged alloy as will be discussed later.

Figure 3 depicts the calculated (0002) and (10 10$)$ pole figures of the samples machined from the crosssection of the forged material at the abovementioned locations and the corner of the beam. To better understand the pole figures, the hexagonal close packed (HCP) grains of the crystallographic microstructure are shown schematically in Figure 3. 


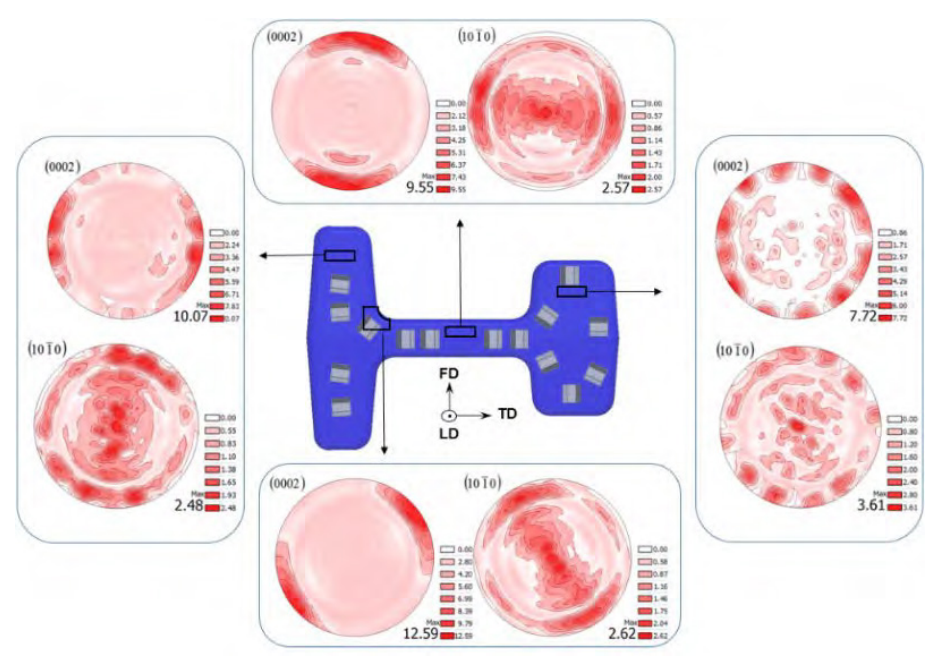

Fig. 3. (0002) and (1010) pole figures for the I-beam forged ZK60 Mg alloy at different locations

According to Figure 3, the plastic deformation as a result of the forging process develops a sharp basal texture in the forged ZK60 at different locations. This texture modification is because of the Rotational Dynamic Recrystallization (RDRX) that rotates the fine grains of the forged material [23]. Nevertheless, the orientation of the c-axis of the HCP grains changes locally. To be more specific, the die cavity provides a small space for the material flow within the web section, which causes severe compressive plastic deformation in the web of the I-beam forging. As a result, most of the HCP grains orient along the forging direction with the maximum pole intensity of 9.55 MRD. In contrast, in the shorter flange, more space is available in the die cavity for the material flow. Therefore, the level of compressive plastic deformation is less than the web and the HCP grains are more randomly distributed in the TD and FD, yet perpendicular to the LD direction. Also, in the taller and thinner flange, a texture with a higher intensity value of 10.07 MRD is induced, and the grains are mostly along the TD direction. The modified texture after the forging process affects the mechanical behaviour as will be discussed later.

Superficial hardness test was performed on the midcross section of the beam. Testing was carried out on 34 locations across the section in a 30 -Ton scale. Figure 4 depicts the Rockwell hardness test results. It is noted that the hardness is roughly symmetric across the beam section. Also, the highest values were observed on the web of the section. This concurs with the microstructure results. It is believed that due to the geometry limitations of the die in the web area, plastic deformation is more severe in this region. Therefore, grains are finer, and material is harder within the web section.

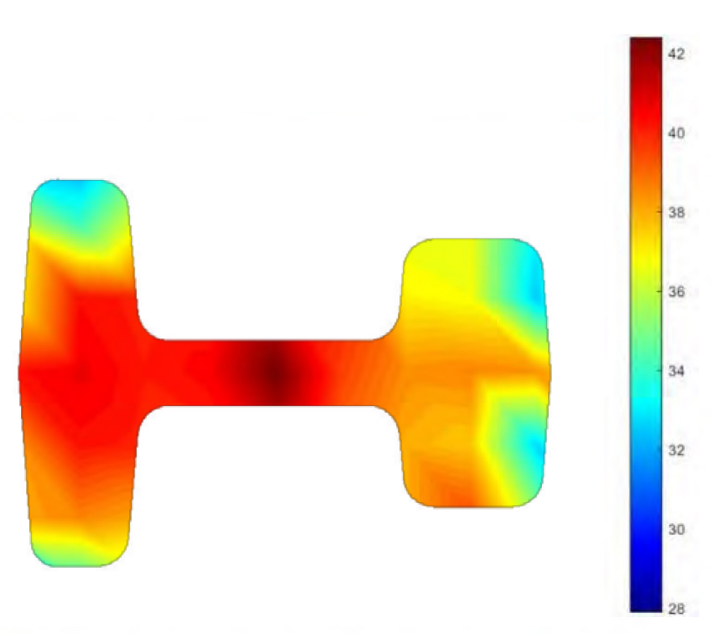

Fig. 4. Rockwell hardness measurement on the cross section of the forged ZK60 Mg alloy in a 30T scale

\subsection{Quasi-static behaviour}

Figure 5 displays the tensile quasi-static behaviour of ascast and cast-forged ZK60 Mg alloy. For the sake of comparison, the effects of open-die forging at the temperature of $450{ }^{\circ} \mathrm{C}$ on the quasi-static behaviour of ZK60 and AZ31B Mg alloys which have already been published in literature are also represented in Figure 5 [11], [13].

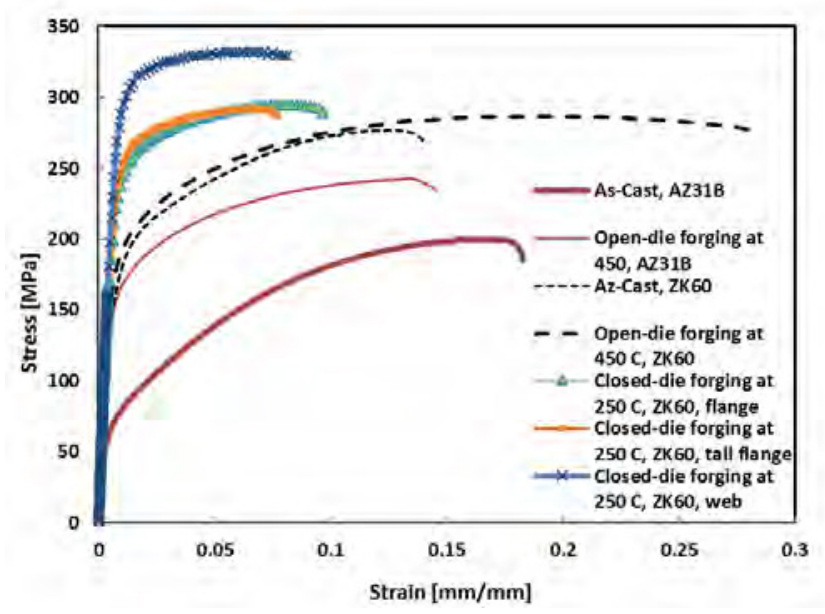

Fig. 5. Tensile quasi-static behaviour of as-cast ZK60 and closed-die forged ZK60 at $250{ }^{\circ} \mathrm{C}$ in the web and flanges of the I-beam

It is noted that the closed-die forging process promisingly enhanced the strength of the alloy comparing to the as-cast condition. While the yield strength of ZK60 cast was $139 \mathrm{MPa}$, the average yields in the two flanges and the web of the forged I-beam were improved to $218 \mathrm{MPa}$ ( $\sim 57 \%$ improvement) and 268 $\mathrm{MPa}(\sim 93 \%$ improvement), respectively. In contrast, the ductility of the alloy was decreased from $15 \%$ to $9 \%$. The average mechanical properties of as-cast, open-die forged [11], and closed-die forged ZK60 Mg alloy is summarized in Figure 6. In this graph, YS and FS 
represent yield strength and fracture strain, respectively. It is believed that the underlying reason for the increase of yield strength and the decrease of ductility after the closed-die forging is the grain refining impact of the process (Figure 2). In fact, the forged alloy is exhibiting higher strength in the wake of its finer grains, thereby higher strength according to the Hall-Petch relation [24]. On the other hand, grain refinement yields higher density of grain boundaries that augments the impedance to the dislocation movement. It is reported that the lack of strain accommodating mechanisms as a result of the increase of barriers to dislocation movement after grain refinement reduces the ductility [25].

Lastly, higher strength is observed in the web of Ibeam in comparison to its flanges. In fact, in this region more severe plastic deformation is occurring as a result of geometry constraints, therefore, grains are finer in the web (Figure 2); hence, the strength of this part is more than that in the I-beam flanges.

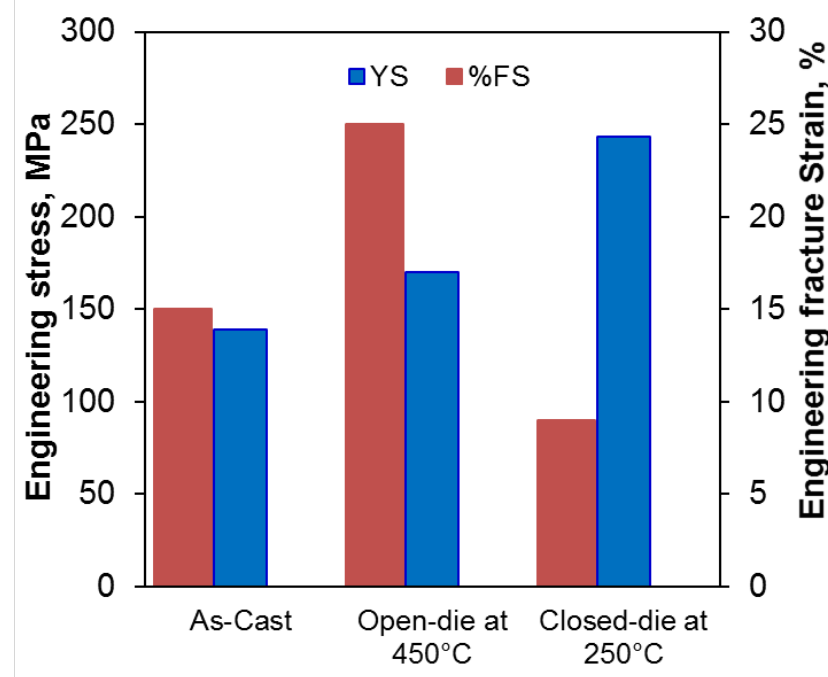

Fig. 6. The yield strength and fracture strain of as-cast, opendie forged [11], and closed-die forged ZK60 Mg alloy

\subsection{Fatigue behaviour}

Fatigue tests were performed under stress-controlled mode at three different stress amplitudes of 140, 160, and $180 \mathrm{MPa}$. Figure 7 demonstrates the S-N results for the as-cast and forged ZK60 Mg alloys. The scatter of the results for the forged condition is because the samples were extracted from different locations in the Ibeam. However, the results revealed an order of magnitude improvement in the life at all the three load levels for the forged condition regardless of the specimen location. For instance, while the fatigue life of the as-cast alloy at the stress amplitude of $140 \mathrm{MPa}$ was 6878 cycles, the average life for the closed-die forged samples was enhanced to 35812 cycles.

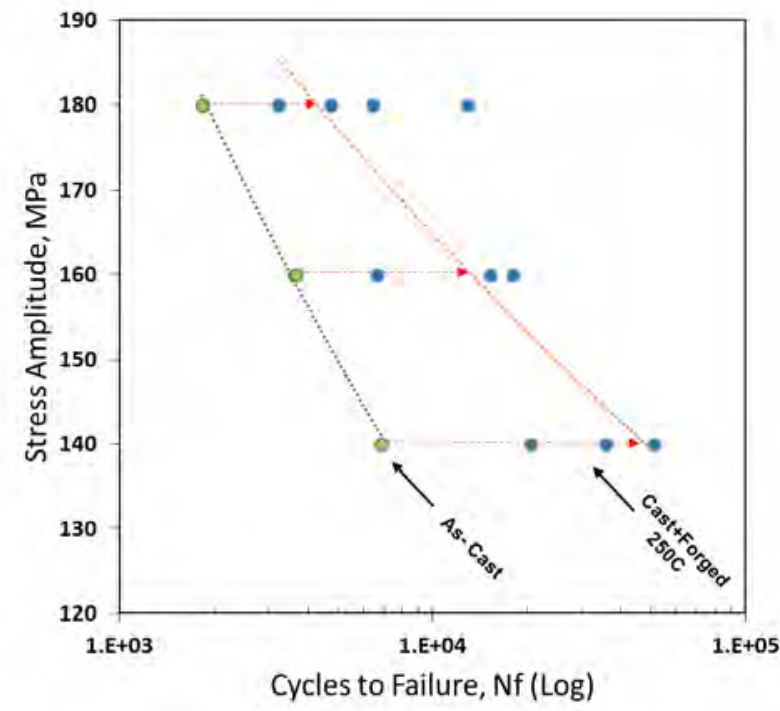

Fig. 8. Stress-controlled fully-reversed push-pull fatigue tests results of as-cast and cast-forged ZK60 Mg alloy

As discussed earlier, microstructural analysis besides texture measurement of the forged part at different locations manifested partial grain refinement and texture modification strengthening mechanisms. It is believed that the fatigue life improvement is achieved in the wake of the grain refinement and the subsequent material strengthening. Indeed, the forged alloy having higher strength exhibited less plastic deformation during the cyclic loading, thereby showing higher number of cycles to accumulate fatigue damage required for the crack initiation. In addition, the finer grains in the microstructure of the forged alloy created more obstacles against the crack propagation which retards the final failure [26]. In contrast, the cast alloy has lower grain boundary density with larger grains serving to increasing the crack propagation rate and lowering the fatigue life.

Furthermore, as was pointed out in section 3.1, the forged alloy showed a strong basal texture. The texture can bring about extension twinning happening once a compressive load is applied along the longitudinal direction of the I-beam. Upon unloading, some twin deformations are recovered, but some residual twins remain inside the microstructure [27]. These residual twins can affect the fatigue response of the alloy in two ways. First, the interactions between the twin-twin bands and also twin-dislocations can lead to the crack initiation causing premature failure [14][28]. Alternatively, some studies have suggested that the extension twinning can elongate the fatigue life in the light of crack growth retardation due to the roughness-induced crack closure [29]. The combination of the abovementioned competing factors leads to the enhanced fatigue response of the forged ZK60.

\section{Conclusions}

In the present study, the effects of closed-die forging on microstructure, texture, quasi-static, and cyclic 
behaviour of cast ZK60 Mg alloy was studied. From the above results and discussions, the following conclusions could be made:

- The forging process brought about grain refinement in the microstructure of the material. The grains in the web of the forged I-beam was finer, since more severe plastic deformation was occurring in that area due to the geometrical constrains.

- The forging process induced sharp basal texture in the crystallographic microstructure of the material so that the c-axes of the most hexagonal grains were perpendicular to the longitudinal direction. This texture modification can activate extension-twinning under high stress amplitudes.

- The yield strength of the closed-die forged alloy was higher than that of the as-cast and open-die forged alloys at higher temperature. The underlying reason for material strengthening was grain refinement and texture modification.

- $\quad$ Forging process improved the stress-controlled fatigue response, considerably. Indeed, at all stress amplitudes, the fatigue life of forged alloy was higher than that of as-cast alloy by an order of magnitude. Grain refinement in the forged part could significantly contribute to the fatigue life improvement by retarding the crack initiation and growth.

- The ultimate goal of this project is to develop knowledge for the adoption of the forged $\mathrm{Mg}$ alloys in the control arm of a massive production passenger car. It is believed that forging is a beneficial manufacturing process for ZK60 Mg alloy to be utilized in the automotive industry, as the strength and fatigue life of the alloy can be improved remarkably.

The authors would like to gratefully acknowledge the financial support of the Natural Sciences and Engineering Research Council of Canada, the Automotive Partnership Canada (APC) program. The authors would also like to thank Jonathan McKinley and Lucian Blaga from CanmentMATERIALS for performing the forging trials.

\section{References}

[1] B. L. Mordike and T. Ebert, "Magnesium Properties - applications - potential," Mater. Sci. Eng. A, vol. 302, no. 1, pp. 37-45, 2001.

[2] M. K. Kulekci, "Magnesium and its alloys applications in automotive industry," Int. J. $A d v$.
Manuf. Technol., vol. 39, no. 9-10, pp. 851-865, 2008.

[3] F. Pan, M. Yang, and X. Chen, "A Review on Casting Magnesium Alloys : Modification of Commercial Alloys and Development of New Alloys," J. Mater. Sci. Technol., vol. 32, no. 12, pp. 1211-1221, 2016.

[4] H. Jahed and J. Albinmousa, "Multiaxial behaviour of wrought magnesium alloys - A review and suitability of energy-based fatigue life model," Theor. Appl. Fract. Mech., vol. 73, pp. 97-108, 2014.

[5] J. Albinmousa, H. Jahed, and S. Lambert, "Cyclic behaviour of wrought magnesium alloy under multiaxial load," Int. J. Fatigue, vol. 33, no. 8, pp. 1127-1139, 2011.

[6] A. A. Roostaei and H. Jahed, "Role of loading direction on cyclic behaviour characteristics of AM30 extrusion and its fatigue damage modelling," Mater. Sci. Eng. A, vol. 670, pp. 2640, 2016.

[7] A. A. Roostaei and H. Jahed, "Multiaxial cyclic behaviour and fatigue modelling of AM30 Mg alloy extrusion," Int. J. Fatigue, vol. 97, pp. 150-161, 2017.

[8] A. Hadadzadeh, M. A. Wells, S. Kumar, H. Jahed, and B. W. Williams, "Role of compression direction on recrystallization behavior and texture evolution during hot deformation of extruded ZK60 magnesium alloy," J. Alloys Compd., vol. 702, pp. 274-289, 2017.

[9] M. Madaj, M. Greger, and V. Karas, "MAGNESIUM-ALLOY DIE FORGINGS FOR AUTOMOTIVE APPLICATIONS," Mater. Tehnol., vol. 49, no. 2, pp. 267-273, 2015.

[10] G. Yu, "Forging Specimen Design for Magnesium Alloys," (Master's Thesis), Retrieved from Univ. Waterloo Database, 2016.

[11] S. M. H. Karparvarfard, S. K. Shaha, S. B. Behravesh, H. Jahed, and B. W. Williams, "Microstructure, texture and mechanical behavior characterization of hot forged cast ZK60 magnesium alloy," J. Mater. Sci. Technol., 2017.

[12] S. M. H. Karparvarfard, S. K. Shaha, A. Hadadzadeh., S. B. Behravesh, H. Jahed, M. A. 
Wells, and B. Williams, "Characterization of Semi-Closed Die-Forged ZK60 Mg Alloy Extrusion," Magnes. Technol. 2017, pp. 329334, 2017.

[13] D. Toscano, S. . Shaha, S. B. Behravesh, H. Jahed, M. A. Wells, B. W. Williams, and J. McKinley, "Effect of Forging on Microstructure, Texture and Uniaxial Properties of Cast AZ31B Alloy," J. Mater. Eng. Perform., vol. 26, no. 7, pp. 3090-3103, 2017.

[14] D. Toscano, S. K. Shaha, B. Behravesh, H. Jahed, and B. Williams, "Effect of forging on the low cycle fatigue behavior of cast AZ31B alloy," Mater. Sci. Eng. A, vol. 706, no. May, pp. 342356, 2017.

[15] D. Toscano, S. K. Shaha, B. Behravesh, H. Jahed, M. Wells, B. Williams, and J. McKinley, "Effect of Forging on Microstructure, Texture and Compression Behavior of Extruded AZ31B," in Proceedings of the 3rd Pan American Materials Congress, Springer International Publishing, 2017, pp. 347-354.

[16] A. Gryguc, H. Jahed, B. Williams, and J. Mckinley, "MagForge - Mechanical Behaviour of Forged AZ31B Extruded Magnesium in Monotonic Compression," Mater. Sci. Forum, vol. 828-829, pp. 291-297, 2015.

[17] A. Gryguc, S. K. Shaha, S. B. Behravesh, H. Jahed, M. Wells, and B. Williams, "Compression Behaviour of Semi-closed Die Forged AZ80 Extrusion," Charact. Miner. Met. Mater. 2017, no. TMS Conference, Location: San Diego, CA, USA, Date: FEB,26-MAR,2, pp. 361-369, 2017.

[18] A. Gryguc, S. K. Shaha, S. B. Behravesh, H. Jahed, M. Wells, B. Williams, and X. Su, "Monotonic and cyclic behaviour of cast and cast-forged AZ80 Mg," Int. J. Fatigue, vol. 104, pp. 136-149, 2017.

[19] A. Gryguc, S.K. Shaha, H. Jahed, M. Wells, B. Williams, J. McKinley, "Tensile and fatigue behaviour of as-forged AZ31B extrusion," Fract. Struct. Integr., vol. 38, pp. 251-258, 2016.

[20] N. Ogawa, M. Shiomi, and K. Osakada, "Forming limit of magnesium alloy at elevated temperatures for precision forging," Int. J. Mach. Tools Manuf., vol. 42, no. 5, pp. 607-614, 2002.

[21] Y. Wu, H. Yan, S. Zhu, J. Chen, A. Liu, and X. Liu, "Flow behavior and microstructure of ZK60 magnesium alloy compressed at high strain rate," Trans. Nonferrous Met. Soc. China, vol. 24, no. 4, pp. 930-939, 2014.

[22] H. Watanabe, K. Moriwaki, T. Mukai, T. Ohsuna, K. Hiraga, and K. Higashi, "Materials Processing for Structural Stability in a ZK60 Magnesium Alloy," Mater. Trans., vol. 44, no. 4, pp. 775-781, 2003.

[23] Y. Xu-yue, J. I. Ze-sheng, H. Miura, and T. Sakai, "Dynamic recrystallization and texture development during hot deformation of magnesium alloy AZ31," Trans. Nonferrous Met. Soc. China, vol. 19, no. 1, pp. 55-60, 2008.

[24] F. Yang, S. M. Yin, S. X. Li, and Z. F. Zhang, "Crack initiation mechanism of extruded AZ31 magnesium alloy in the very high cycle fatigue regime," Mater. Sci. Eng. A, vol. 491, pp. 131136, 2008.

[25] C. M. Cepeda-Jimenez, J. M. Kolina-Aldareguia, and M. T. Perez-Prado, "Effect of grain size on slip activity in pure magnesium polycrystals," Acta Mater., vol. 84, pp. 443-456, 2015.

[26] M. Tsushida, K. Shikada, H. Kitahara, S. Ando, and H. Tonda, "Relationship between Fatigue Strength and Grain Size in AZ31 Magnesium Alloys," Mater. Trans., vol. 49, no. 5, pp. 11571161, 2008.

[27] L. Wu, A. Jain, D. W. Brown, G. M. Stoica, S. R. Agnew, B. Clausen, D. E. Fielden, and P. K. Liaw, "Twinning-detwinning behavior during the strain-controlled low-cycle fatigue testing of a wrought magnesium alloy, ZK60A," Acta Mater., vol. 56, no. 4, pp. 688-695, 2008.

[28] H. Yu, Y. Xin, A. Chapuis, X. Huang, R. Xin, and Q. Liu, "The different effects of twin boundary and grain boundary on reducing tension-compression yield asymmetry of $\mathrm{Mg}$ alloys,” Nat. Publ. Gr., no. May, pp. 4-11, 2016.

[29] Y. J. Wu, R. Zhu, J. Tao, and W. Qing, "Role of twinning and slip in cyclic deformation of extruded $\mathrm{Mg}-3 \% \mathrm{Al}-1 \% \mathrm{Zn}$ alloys," Scr. Mater., vol. 63, no. 11, pp. 1077-1080, 2010. 